\title{
Sea State Effect on the Sea Surface Emissivity at L-Band
}

\author{
Jorge José Miranda, Mercè Vall-llossera, Member, IEEE, Adriano Camps, Senior Member, IEEE, \\ Núria Duffo, Member, IEEE, Ignasi Corbella, Member, IEEE, and Jacqueline Etcheto
}

\begin{abstract}
In May 1999, the European Space Agency (ESA) selected the Earth Explorer Opportunity Soil Moisture and Ocean Salinity (SMOS) mission to obtain global and frequent soil moisture and ocean salinity maps. SMOS single payload is the Microwave Imaging Radiometer by Aperture Synthesis (MIRAS), an L-band two-dimensional aperture synthesis radiometer with multiangular observation capabilities. At L-band, the brightness temperature sensitivity to the sea surface salinity (SSS) is low, approximately $0.5 \mathrm{~K} / \mathrm{psu}$ at $20{ }^{\circ} \mathrm{C}$, decreasing to $0.25 \mathrm{~K} / \mathrm{psu}$ at $0{ }^{\circ} \mathrm{C}$, comparable to that to the wind speed $\sim 0.2 \mathrm{~K} /(\mathrm{m} / \mathrm{s})$ at nadir. However, at a given time, the sea state does not depend only on local winds, but on the local wind history and the presence of waves traveling from far distances. The Wnd and Salinity Experiment (WISE) 2000 and 2001 campaigns were sponsored by ESA to determine the impact of oceanographic and atmospheric variables on the $L$-band brightness temperature at vertical and horizontal polarizations. This paper presents the results of the analysis of three nonstationary sea state conditions: growing and decreasing sea, and the presence of swell. Measured sea surface spectra are compared with the theoretical ones, computed using the instantaneous wind speed. Differences can be minimized using an "effective wind speed" that makes the theoretical spectrum best match the measured one. The impact on the predicted brightness temperatures is then assessed using the small slope approximation/small perturbation method (SSA/SPM).
\end{abstract}

Index Terms-Nonstationary sea conditions, sea surface emissivity at L-band, sea surface spectrum, swell effect.

\section{INTRODUCTION}

$\mathbf{K}$ NOWLEDGE of the distribution of salt in the ocean and its annual and interannual variability are crucial in understanding the role of the ocean in the climate system. The measurement of the sea surface salinity (SSS) is one of the challenges of the European Space Agency's (ESA) Soil Moisture and Ocean Salinity (SMOS) Earth Explorer Opportunity mission. SMOS single payload is the Microwave Imaging Radiometer by Aperture Synthesis (MIRAS), a two-dimensional (2-D) L-band synthetic aperture radiometer with full-polarimetric capability. Two-dimensional brightness

Manuscript received October 14, 2002; revised June 30, 2003. This work was supported by the Spanish Comisión Interministerial de Ciencia y Tecnología (CICYT TIC99-1050-C03-01) and by Grant "Distinció de Recerca de la Generalitat de Catalunya," resolution: UNI/2120/2002 on July 19th, DOGC 3684, 24/07/2002. The WISE 2000 and 2001 field campaigns have been sponsored by the European Space Agency under ESTEC contract 14188/00/NL/DC.

J. J. Miranda, M. Vall-llossera, A. Camps, N. Duffo, and I. Corbella are with the Technical University of Catalonia (UPC), E-08034, Barcelona, Spain (e-mail: miranda@tsc.upc.es).

J. Etcheto is with Laboratoire d'Océanographie Dynamique et Climatologie (LODYC), UPMC, F-75252 Paris Cedex 05, France.

Digital Object Identifier 10.1109/TGRS.2003.817190 temperature images will provide looks of the same pixel under incidence angles from $0^{\circ}$ to almost $65^{\circ}$, which requires the development of soil and sea emission models in the whole range of incidence angles, and suitable geophysical parameters retrieval algorithms.

The dielectric permittivity for seawater is determined, among other variables, by salinity. Therefore, in principle, it is possible to retrieve SSS from passive microwave measurements as long as the variables influencing the brightness temperature (TB) signal (sea surface temperature, roughness, and foam) can be accounted for at different viewing angles, polarizations, and frequencies. The sensitivity of TB to SSS is maximum at low microwave frequencies, and good conditions for salinity retrieval are found at L-band $(1.4 \mathrm{GHz})$. However, even at this frequency, the sensitivity of TB to SSS is still low $(\sim 0.5 \mathrm{~K} / \mathrm{psu}$ for a sea surface temperature $\mathrm{SST}=20^{\circ} \mathrm{C}$, decreasing to $\sim 0.25 \mathrm{~K} / \mathrm{psu}$ for SST $\left.=0{ }^{\circ} \mathrm{C}\right)$, which is comparable to that to the wind speed $(\sim 0.2 \mathrm{~K} /(\mathrm{m} / \mathrm{s})$ at nadir). Consequently, it places demanding requirements on both the performance of the instrument, and the geophysical modeling of the sea surface and its emissivity.

The SSS retrieval algorithms for the SMOS mission must then include: 1) the variation of the local incidence angle, as a pixel appears in consecutive snap-shots, and eventually 2) the azimuthal variation of the sea emissivity or sea emission azimuthal signature. These two points require an accurate modeling of the sea surface emissivity at L-band. However, until recently, experimental data were very scarce. The main goal of the ESA-sponsored Wind and Salinity Experiment (WISE) 2000 and 2001 campaigns was to determine the TB sensitivity to wind speed (or sea state) [1], [2]. The campaigns took place at Repsol's Casablanca oil rig, located at $40^{\circ} 43.02^{\prime} \mathrm{N} 1^{\circ} 21.50^{\prime} \mathrm{E}$, $40 \mathrm{~km}$ away from the Ebro River mouth on the coast of Tarragona, Spain. The sea bed is $165 \mathrm{~m}$, and the sea conditions are representative of the Mediterranean shelf/slope region with periodic influence of the Ebro River fresh water plume. WISE 2000 data acquisition spanned from November 25 to December 18, 2000 and from January 8 to January 15, 2001, and WISE 2001 from October 23 to November 22, 2001.

It is known that the wind is the major disturbing force of the sea surface [3]. In WISE 2000 and 2001, part of the discrepancies between the brightness temperature data and the brightness temperature computed using instantaneous local wind speed are attributed to wave reflections in the oil rig structure, the presence of waves originated by winds that have blown far away, and sea state conditions different from those of fully developed sea [4].

In Section II, a description of some sea surface roughness models and the involved parameters are presented. Then, in 


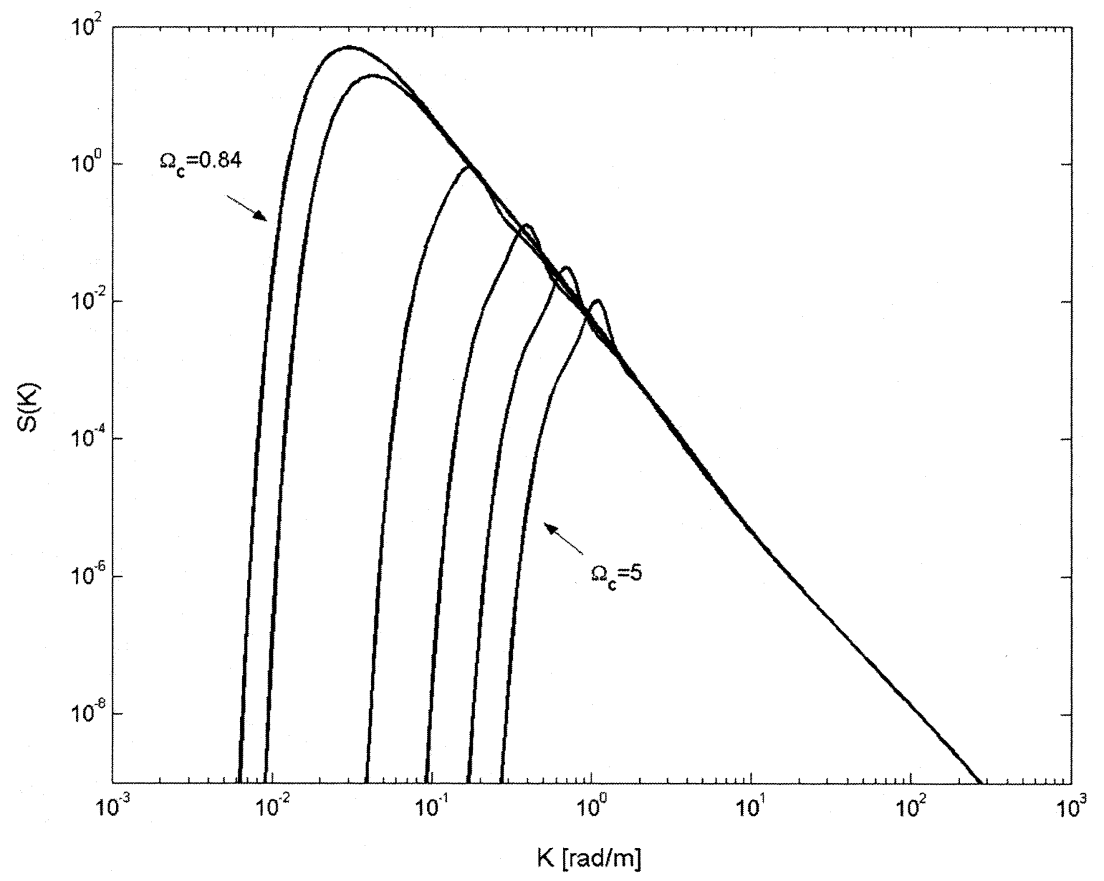

Fig. 1. Dependence of the unified omnidirectional spectrum with the inverse-wave-age (the used values of $\Omega_{c}$ are $0.84,1,2,3,4$, and 5). Wind speed is $15 \mathrm{~m} / \mathrm{s}$.

Section III, the most representative climatologic conditions occurred during WISE campaigns are analyzed. In fact, we present an intercomparison of measured spectra in WISE campaigns with the ones computed by models when the simultaneously measured wind speed is applied. Finally, the difference between the brightness temperatures for both spectra (measured and theoretical depending only with the instantaneous wind speed) is obtained. It is demonstrated that this difference is comparable to the brightness temperature SSS signature. Therefore, in order to achieve the required accuracy in SSS retrieval, it is necessary to know the actual sea state conditions and not only the instantaneous wind speed.

\section{Modeling the Sea State}

The statistical description of the sea surface is represented by its directional spectrum $\psi(k, \phi)$, defined as the Fourier transform of the autocorrelation function of the surface height. Sea state evolves both in time and space. The evolution of spectral sea surface components at $k$ wavenumber, traveling in the $\phi$ direction, along a distance $x$, during a time $t$, follows the energy balance or transport equation for deep-water [5]

$$
\frac{\partial}{\partial t} \Psi(k, \theta ; x, t)+c_{g} \cdot \nabla \Psi(k, \theta ; x, t)=S_{i}+S_{d}+S_{\mathrm{nl}}
$$

where $c_{g}$ is the group speed. The right-hand side of (1) adds the wind energy input $\left(S_{i}\right)$, the dissipation $\left(S_{d}\right)$, and the transference of energy among frequency components due to nonlinear interactions $\left(S_{\mathrm{nl}}\right)[6]$.

Due to frictional drag in the air-surface interface, first short capillary waves are developed. Part of the capillary wave energy is then transferred to longer wavelength gravity waves, and as time elapses the wavelength associated to the spectral peak and total energy increase. This process continues until an equilibrium state, in which the input wind energy balances the energy dissipation, is reached. In this state, the sea is said to be fully developed. The time necessary to develop gravity waves is then higher than that to develop capillary waves. When wind stops, short waves disappear rapidly, while long waves take longer and may last for several days, which allows them to propagate over long distances and add to locally generated waves. This phenomenon is usually known as swell, and it is considered to contain wave-periods higher than $10 \mathrm{~s}$, approximately [7].

The directional spectrum $\Psi(k, \phi)[(1)]$ is divided into the omnidirectional spectrum $S(k)$ and the angular spreading function $\Phi(k, \phi)[(2)]$

$$
\Psi(k, \phi)=\frac{1}{k} \cdot S(k) \cdot \Phi(k, \phi) .
$$

The spreading function, which is even and real, can be decomposed by a Fourier series expansion

$$
\Phi(k, \phi)=\frac{1}{2 \pi}\left[1+\sum_{n=1}^{\infty} a_{2 n} \cdot \cos (2 n \phi)\right]
$$

and it is usually approximated with the two first terms [8]

$$
\Phi(k, \phi) \simeq \frac{1}{2 \pi}\left[1+\sum_{n=1}^{\infty} a_{2 n} \cdot \cos (2 n \phi)\right] .
$$

Many sea roughness spectrum models have been developed. A comprehensive description of them is presented in [8]. However, most of them assume fully developed sea state conditions, a situation that requires that the wind blows at constant speed and direction during a given time and distance. Fully developed sea spectra depend only on the wind measured at a reference height. In this work, we use the wind speed measured at $10 \mathrm{~m}$ $\left(U_{10}\right)$. The distance that a constant wind vector covers is called fetch ( $x$, in meters), and its dimensionless value is $X=k_{0} \cdot x$, where $k_{0}$ is the wavenumber, defined as $k_{0}=g / U_{10}^{2}$ [9]. As the wind speed increases, both fetch and wind action time must 


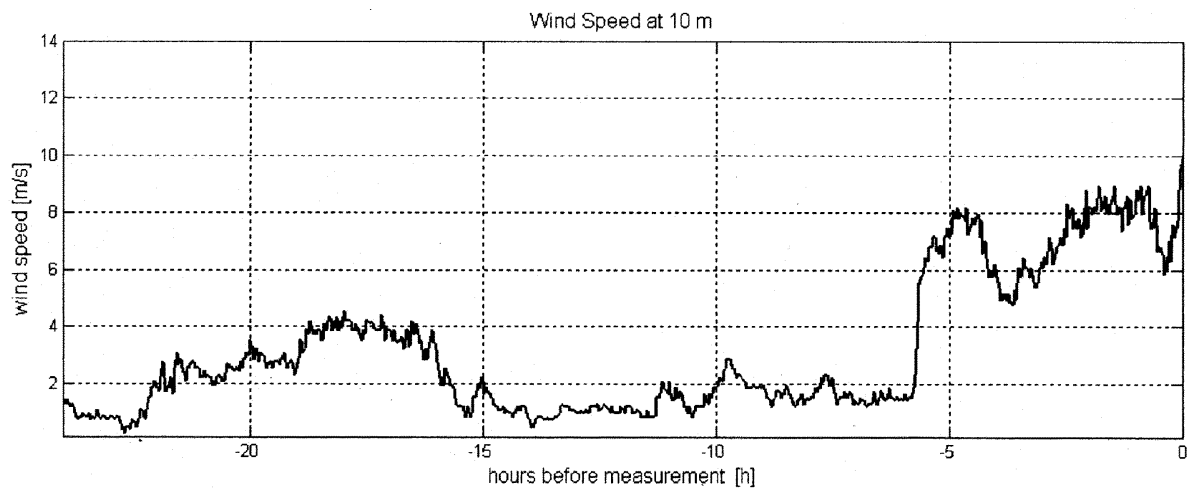

(a)

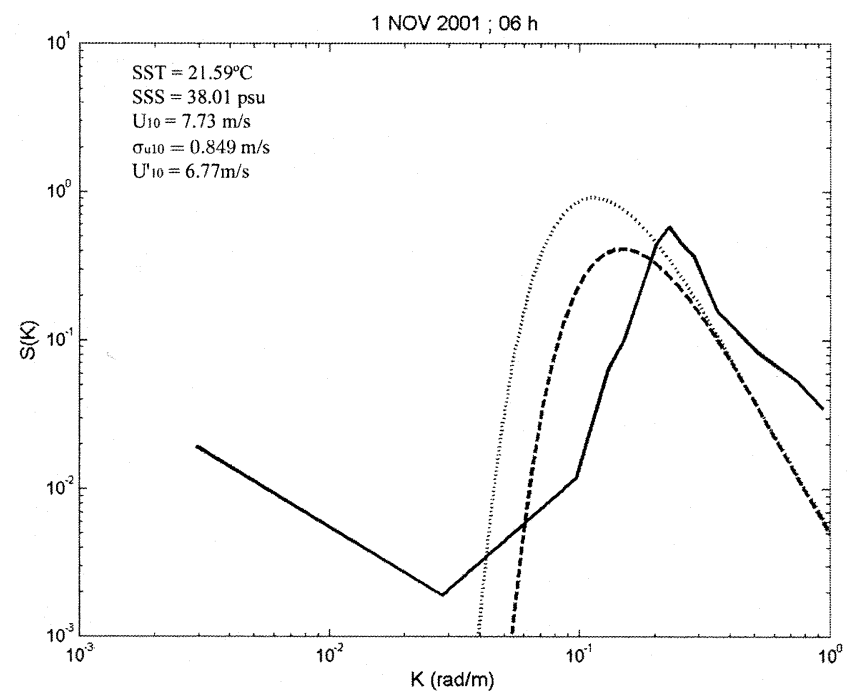

(b)

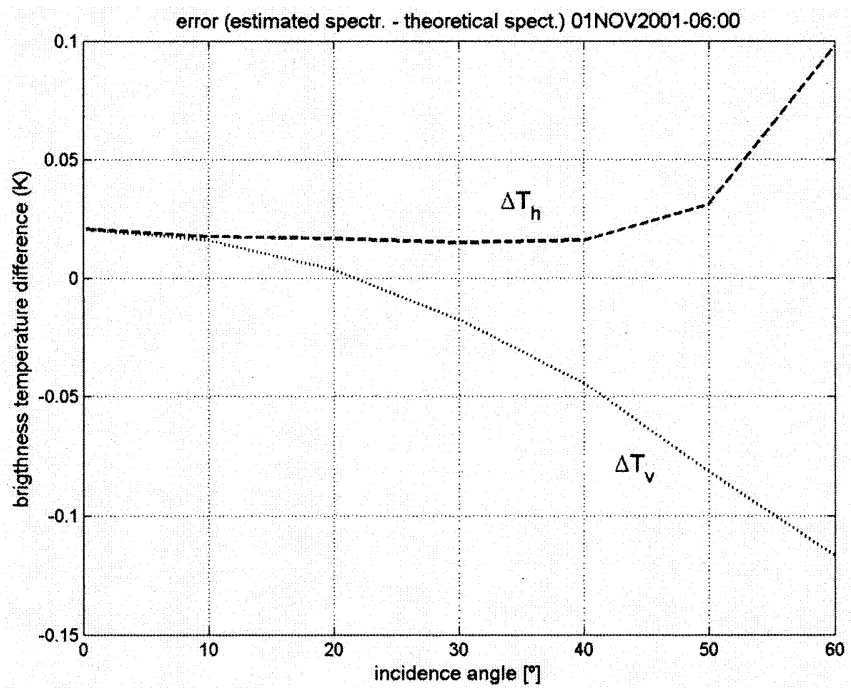

(c)

Fig. 2. Growing sea case. (a) Wind speed referred to 10-m height during $24 \mathrm{~h}$ before the nominal measurement time. (b) Buoy-measured spectrum (solid line), unified spectrum computed with the equivalent wind speed $U_{10}^{\prime}=6.77 \mathrm{~m} / \mathrm{s}$ (dotted line), and unified spectrum computed with the 3-h averaged wind speed measured at $10-\mathrm{m}$ height $\bar{U}_{10}=7.73 \mathrm{~m} / \mathrm{s}$ (dashed line). (c) Difference of brightness temperature at vertical (dotted line) and horizontal (dashed line) polarizations computed with the SSA/SPM method using the theoretical unified spectrum calculated with $U_{10}^{\prime}=6.77 \mathrm{~m} / \mathrm{s} \mathrm{minus} \mathrm{the} \mathrm{one} \mathrm{obtained} \mathrm{with} \mathrm{the} \mathrm{measured} \mathrm{wind} \mathrm{speed}$ $\bar{U}_{10}=7.73 \mathrm{~m} / \mathrm{s}$. The error is positive for the horizontal polarization and negative for the vertical polarization in accordance with a spectrum overestimation.

increase to reach the conditions of fully developed sea [3]. In WISE experiments, because of the oil rig situation (see the introduction), in most cases when the wind blows from the west or northwest, the sea cannot be considered fully developed. Dominant winds in the Casablanca oil rig are from the north and northwest. Winds from the South are much rarer.

From the study of an extensive dataset of developing sea states, Donelan et al. [10] and Dobson [11] obtained a dependence of the long-wave spectrum with the dimensionless inverse-wave-age parameter $\Omega=g / U_{10}^{2}$, where $c_{\mathrm{p}}$ is the wave phase speed at the spectral peak. Taking into account the relationship between the dimensionless energy with the fetch [12], Elfouhaily [8] derived the following fetch to inverse-wave-age relationship:

$$
\begin{aligned}
& \Omega_{c}=0.84 \tanh \left[\left(\frac{X}{X_{0}}\right)^{0.4}\right]^{-0.75} \\
& X_{0}=2.2 \cdot 10^{4}, \Omega_{c}=\Omega \cos \Theta
\end{aligned}
$$

where $\Theta$ is the angle between the wind and the dominant waves at the spectral peak and its value is always close to zero, and then
$\Omega \approx \Omega_{c}$. Seas are said to be fully developed, mature and young when $\Omega_{c}$ has values closed to $0.84,1$ and $>2$, respectively. Fig. 1 shows the strong dependence of the unified omnidirectional spectrum, described in [8] (wind speed equal to $15 \mathrm{~m} / \mathrm{s}$ ) with the inverse-wave-age ( $\Omega_{c}$ varying from 0.84 to 5$)$.

Section III presents some plots of measured wind speed and spectra during WISE campaigns, showing that in most conditions the sea state cannot be considered fully developed. The impact of sea state on the brightness temperatures is evaluated using the small slope approximation/small perturbation method (SSA/SPM) model [13], [14]. This model provides good agreement with measured $T_{B}$ and its sensitivity to wind speed.

\section{Sea State in Nonstationary Conditions: Impact ON THE BRIGHTNESS TEMPERATURE AT L-BAND}

During WISE campaigns wind speeds at 2.6- and 69-m height were recorded and referred to $10 \mathrm{~m}$ using the following [15]:

$$
U_{z}=\frac{U_{*}}{0.4} \ln \left(\frac{z}{z_{0}}\right) \mathrm{cm} / \mathrm{s}
$$




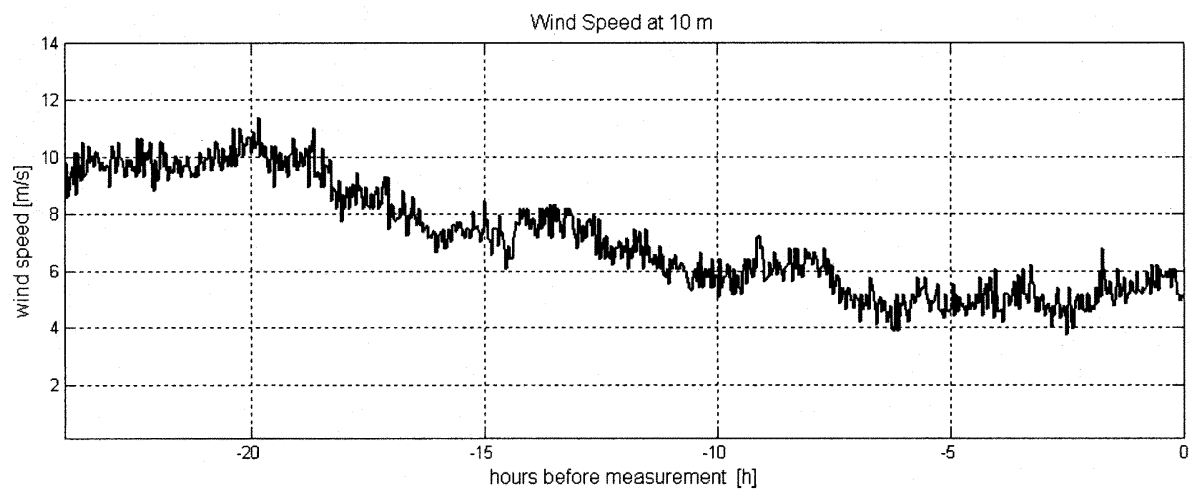

(a)

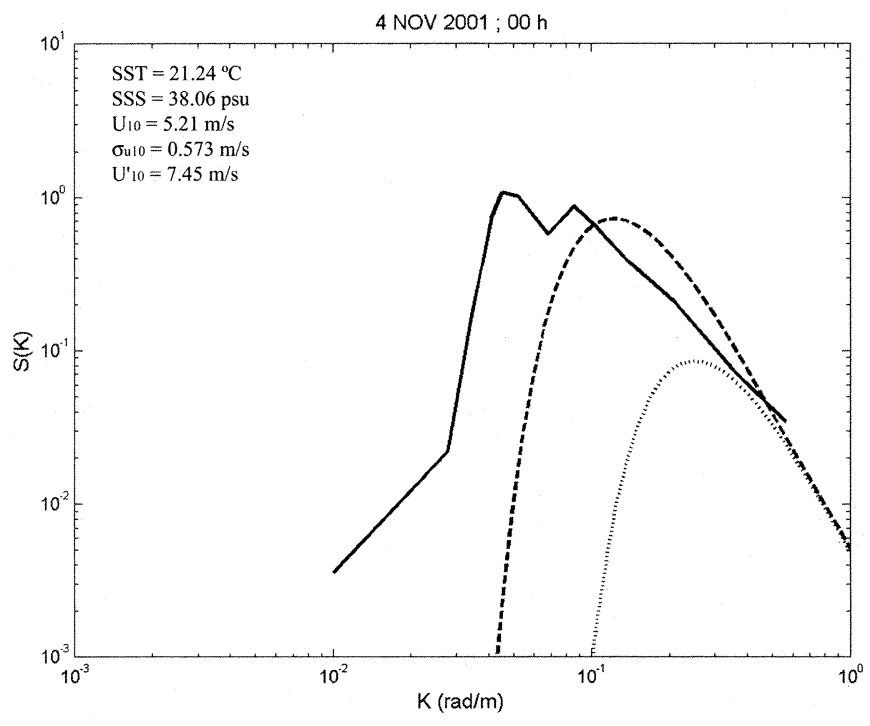

(b)

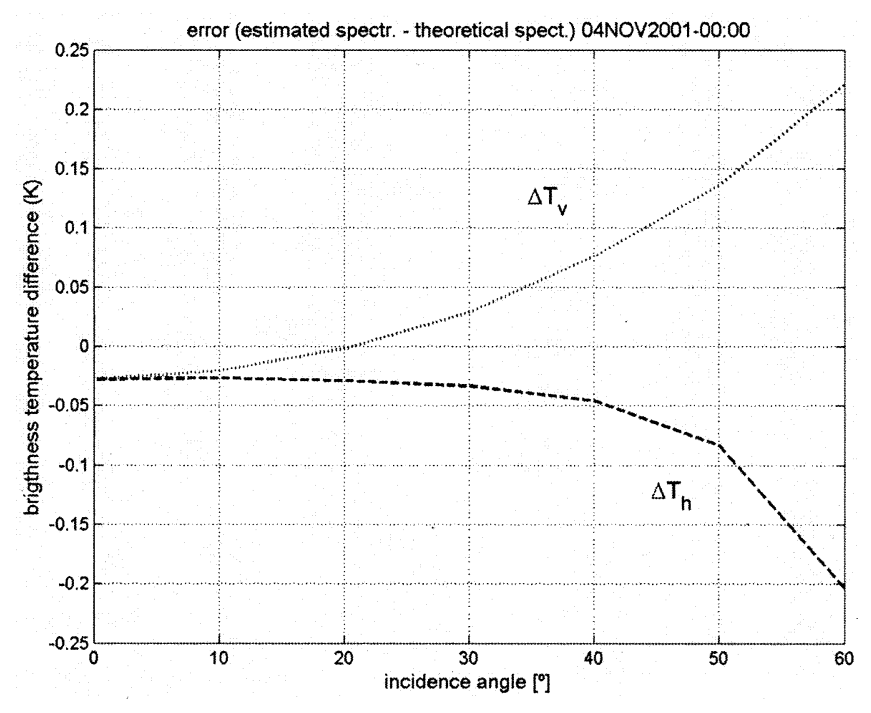

(c)

Fig. 3. Decreasing sea case. (a) Wind speed referred to 10 - $\mathrm{m}$ height during $24 \mathrm{~h}$ before the nominal measurement time. (b) Buoy-measured spectrum (solid line), unified spectrum computed with the equivalent wind speed $U_{10}^{\prime}=7.45 \mathrm{~m} / \mathrm{s}$ (dotted line) and unified spectrum computed with the 3-h averaged wind speed measured at $10 \mathrm{~m} \bar{U}=5.21 \mathrm{~m} / \mathrm{s}$ (dashed line). (c) Difference of brightness temperature at vertical (dotted line) and horizontal (dashed line) polarizations computed with the SSA/SPM method with the theoretical unified spectrum calculated with $U_{10}^{\prime}=7.45 \mathrm{~m} / \mathrm{s}$ and $\bar{U}_{10}=5.21 \mathrm{~m} / \mathrm{s}$. The error is positive for the vertical polarization and negative for the horizontal polarization in accordance with a spectrum underestimation.

where $U_{z}$ and $U_{*}$ are the wind speed at height $z$ and the friction speed, respectively, and $z_{0}$ is obtained from

$$
z_{0}=\frac{6.84 \cdot 10^{-5}}{U_{*}}+4.28 \cdot 10^{-3} \cdot U_{*}^{2}-4.43 \cdot 10^{-4}
$$

Furthermore, the sea surface elevation spectra were simultaneously measured by a wave-rider buoy. During $3 \mathrm{~h}$, the buoy measures the sea height, and then, it is Fourier transformed. Nevertheless, the measured spectra are defined with only 14 points and the accuracy of the numerical method depends on the number of points used in the numerical integration of the sea surface spectrum. Hence, the energy of each measured spectrum has been obtained, and then, an equivalent wind speed $\left(U_{10}^{\prime}\right)$ has been estimated in order to compute a unified wind driven spectrum with the same energy as the measured one. The $T_{B}$ computed with the wind driven spectrum for the equivalent wind speed $\left(U_{10}^{\prime}\right)$, at different representative moments during WISE campaigns, were compared with the $T_{B}$ computed with the wind driven spectrum applying the simultaneously measured wind speed. In fact, in order to be consistent with the 3-h measurements of the buoy, it has been used the average of wind speeds recorded during the $3 \mathrm{~h}$ of the buoy measurements $\left(\bar{U}_{10}\right)$. Three events are presented below as examples of three real sea conditions: growing sea, decreasing sea and sea affected by swell. None of their spectra is well characterized by fully developed models.

The brightness temperatures were computed using the second-order SSA/SPM emissivity model [16]. Johnson and Zhang recall a theoretical development of this method in [13]. In that paper, the physics of the emission process predicted by SSA/SPM was clarified. The use of the SSA/SPM up to the second-order obtains an expansion in surface slope, with zero-order terms reproducing flat surface emission results, first-order terms identically zero, and the second-order terms providing the first prediction of changes from flat surface brightness. Second-order terms take the form of an integral of a set of weighting functions over the surface directional spectrum. Properties of a directional spectrum result in no first harmonic variation being obtained; a third-order SSA/SPM is 


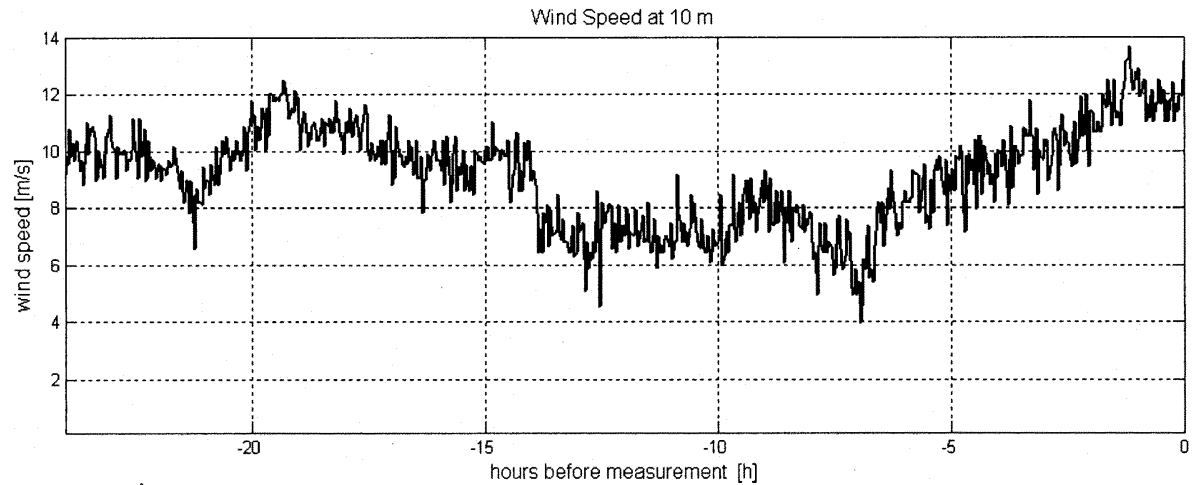

(a)

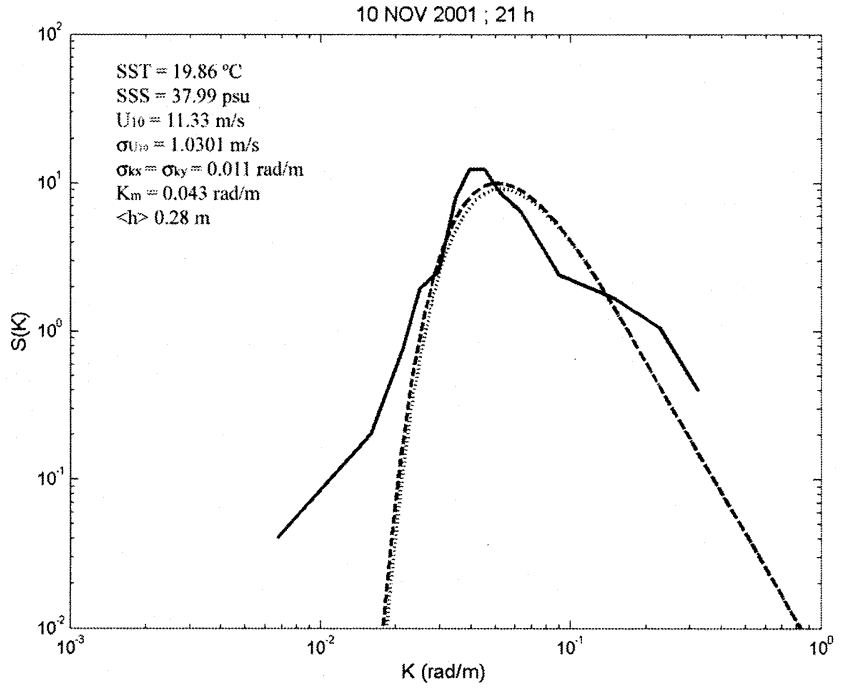

(b)

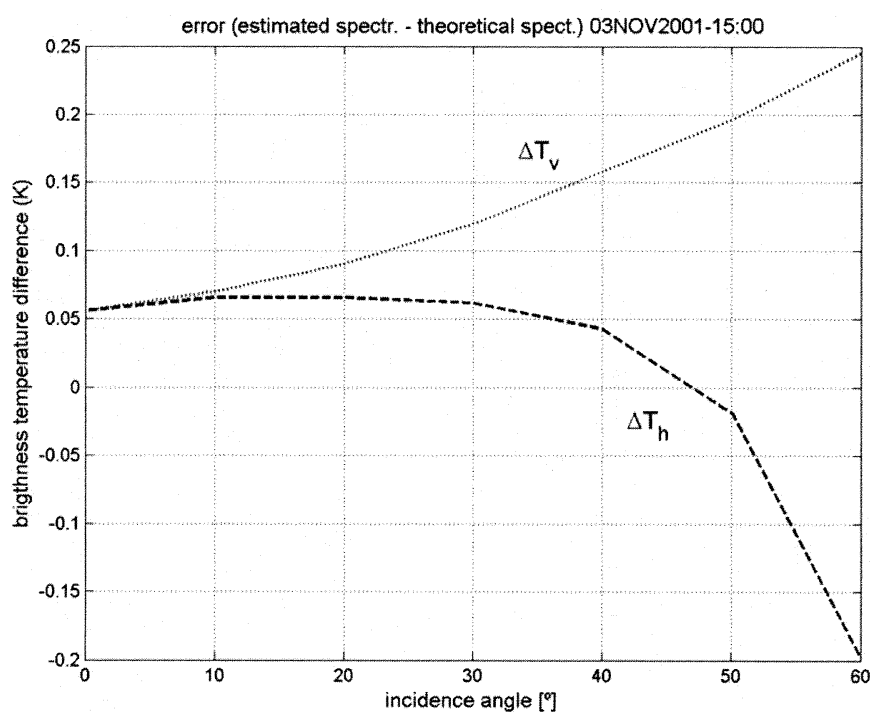

(c)

Fig. 4. Swell case. (a) Wind speed referred to 10-m height during $24 \mathrm{~h}$ before the nominal measurement time. (b) Buoy-measured spectrum (solid line), unified spectrum computed with the 3-h averaged wind speed measured at $10-\mathrm{m}$ height $\bar{U}_{10}=11.33 \mathrm{~m} / \mathrm{s}$ (dotted line) and the same spectrum plus swell spectrum with the parameters shown in the box (dashed line). (c) Difference of brightness temperature at vertical (dotted line) and horizontal (dashed line) polarizations computed with the SSA/SPM method with the theoretical unified spectrum calculated with the equivalent wind speed and the averaged measured wind speed. The swell increases the roughness. The error is positive for the vertical polarization and negative for the horizontal polarization in accordance with a spectrum underestimation.

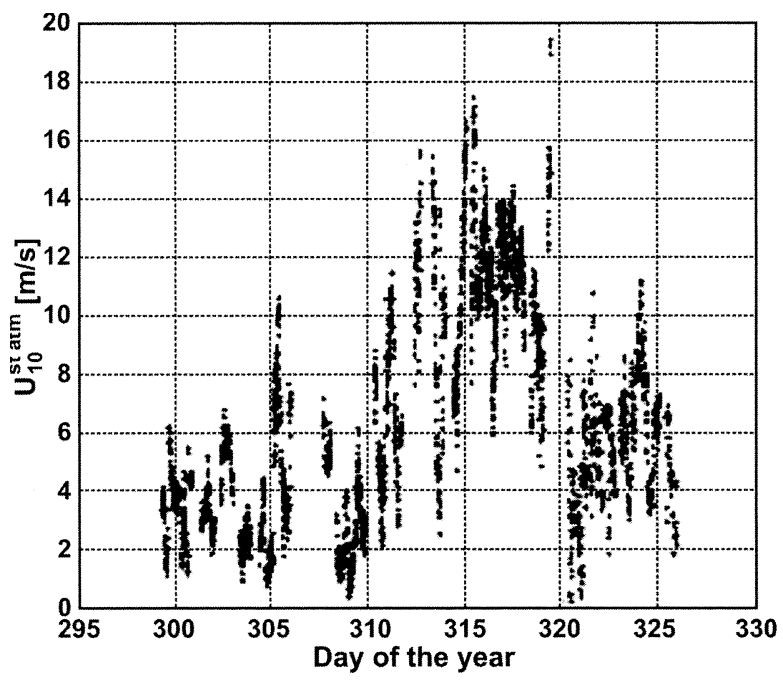

(a)

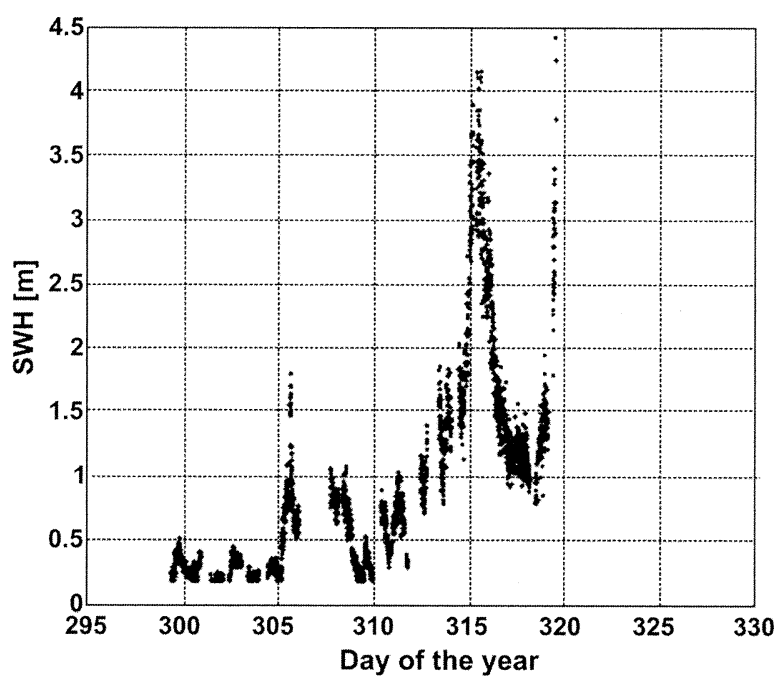

(b)

Fig. 5. (a) Significant wave height (SWH) defined as H1/3 the average of the highest third of the waves [m], and (b) maximum wave period [s] from October 15 to November 22, 2001. 


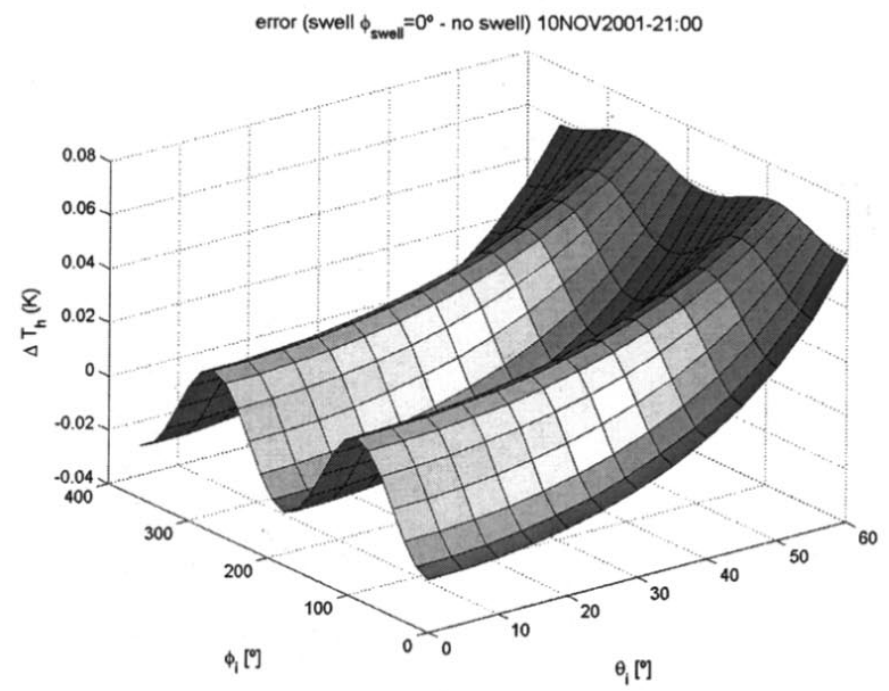

(a)

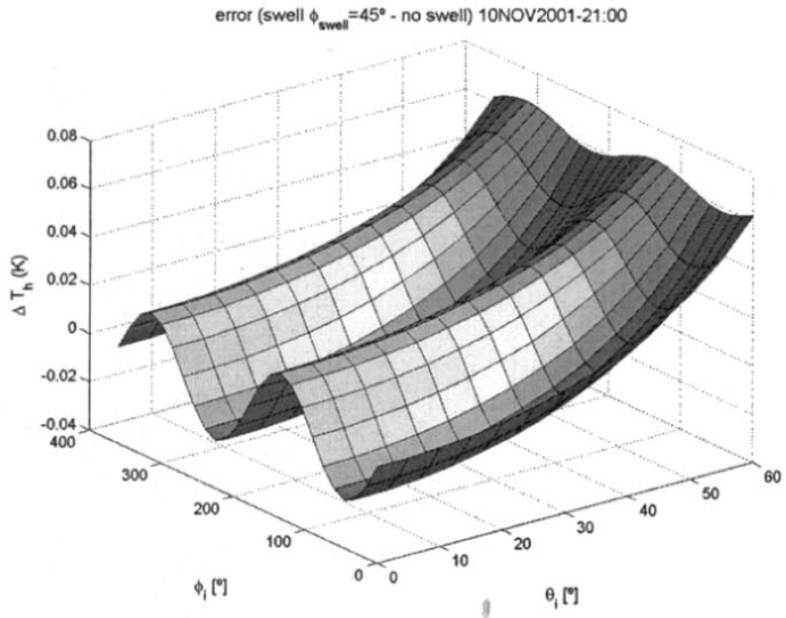

(c)

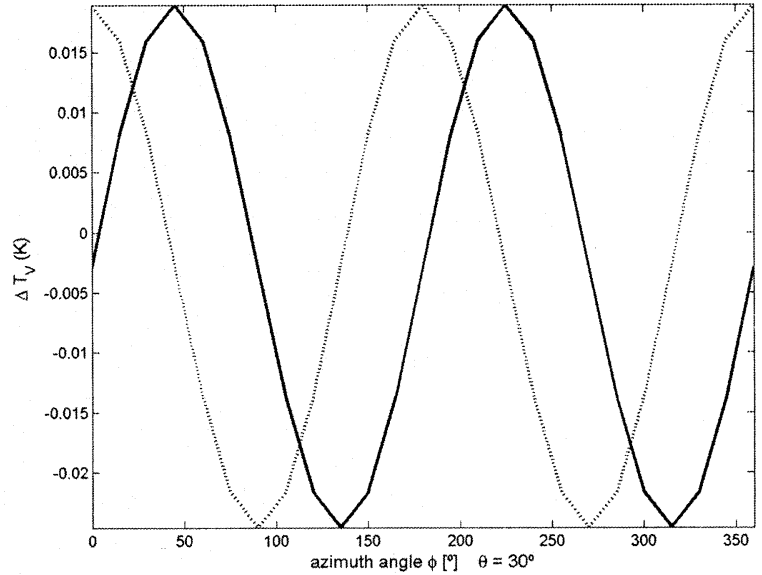

(e)

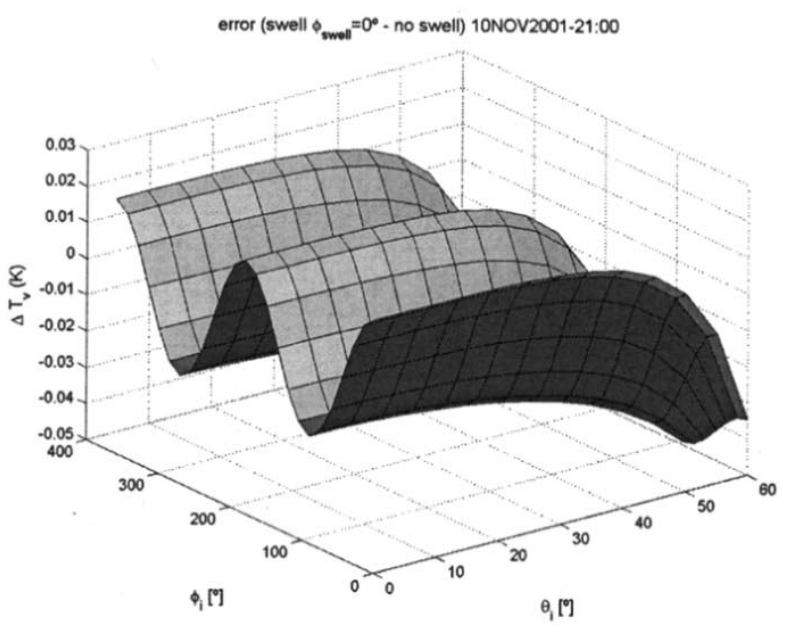

(b)

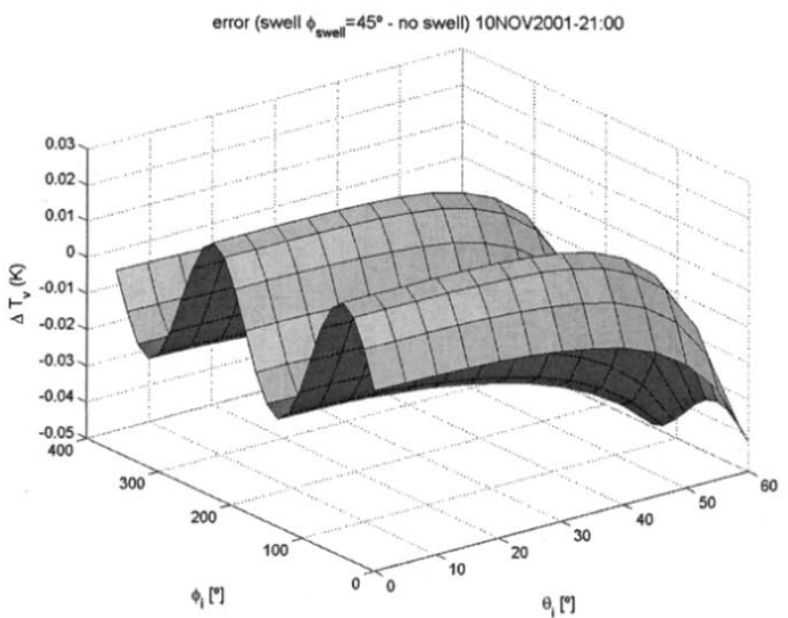

(d)

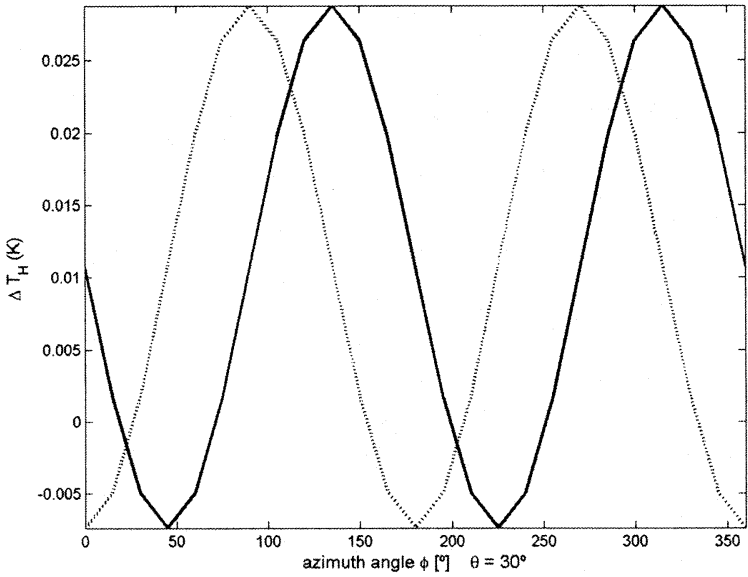

(f)

Fig. 6. Brightness temperature difference between the unified theoretical spectrum without swell and with swell. (a) and (c) Result for the horizontal polarization. (b) and (d) Result for the vertical polarization. In (a) and (b), the swell direction relative to the wind direction is $0^{\circ}$. In (c) and (d), the swell direction is $45^{\circ}$ respect to the wind direction. Plot (e) compares the cuts at $\theta=30^{\circ}$ in (a) and (c), and plot (f) compares the cuts at $\theta=30^{\circ}$ in (b) and (d). The objective of (e) and (f) is to show the shifting in the error signature due to the angle between the wind and the swell directions. 
required to obtain the first harmonics. Only the second-order expansion is considered in this study. No artificial cutoff wavenumber is required to separate small and large scale waves in this method.

\section{A. Growing Sea}

Fig. 2 corresponds to measurements held on November 1, 2001 at 6 A.M. (day of year $=305$ ) and shows an example of a growing sea that has not reached the fully developed conditions. The wind speed evolution during the previous $24 \mathrm{~h}$ is presented in Fig. 2(a), and shows two wind speed jumps: the first one $6 \mathrm{~h}$ before the measurement and the second one only half an hour. A large discrepancy between the measured spectrum (solid line) and the unified spectrum for a fully developed sea (dotted line) computed with the 3 -h averaged wind speed at $10 \mathrm{~m}$ from sea level, $\bar{U}_{10}=7.73 \mathrm{~m} / \mathrm{s}$, is observed in Fig. 2(b). The measured spectrum could also be approximated using an inverse-wave-age larger than 0.84 (fully developed sea), which means that the sea has not reached maturity conditions. Nevertheless, the disagreement is still considerable. This is because the theoretical growing spectrum is the transient state between a flat sea and the fully developed sea under a constant wind blowing for a quite long time, whereas the actual situation is the sum of nonconstant local wind effect, plus the contribution of the energy propagated from remote places. An equivalent wind speed $U^{\prime}=6.27 \mathrm{~m} / \mathrm{s}$ has been obtained. This wind speed has an associated unified spectrum [dashed line in Fig. 2(b)] with the same energy as the measured one. Fig. 2(c) shows the difference between the brightness temperatures computed by SSA/SSPM for the fully developed unified spectra with $U_{10}^{\prime}$ (same energy than measurement) and $\bar{U}_{10}$ (average of 3-h measured wind speed). The error is negligible at nadir, but increases with elevation angle reaching values around $+0.1 \mathrm{~K}$ and $-0.12 \mathrm{~K}$ for $T_{h}$ and $T_{v}$, respectively. As compared to the salinity brightness temperature signature (see the introduction), these values are not negligible at all.

\section{B. Decreasing Sea}

Fig. 3 corresponds to measurements on November 4, 2001 at 12 A.M. (day of year $=308$ ) and represents an example of a decreasing sea. The wind speed evolution during the previous $24 \mathrm{~h}$ is plotted in Fig. 3(a). The wind speed tends to decrease from $20 \mathrm{~h}$ before the measurement. Fig. 3(b) shows the measured spectrum (solid line), the unified spectrum for a fully developed sea for the $3-\mathrm{h}$ averaged wind speed at $10 \mathrm{~m} \bar{U}=5.21 \mathrm{~m} / \mathrm{s}$ (dotted line) and the unified spectrum for a fully developed sea considering the equivalent wind speed $U_{10}^{\prime}=7.45 \mathrm{~m} / \mathrm{s}$ (dashed line). As expected, the measured spectrum shows a greater contribution of the long waves than the corresponding theoretical fully developed spectrum. In general, the inertia of the long waves creates a remnant roughness over the sea surface, which propagates long distances and leads to the appearance of swell (example C).

Fig. 3(c) shows the difference between the brightness temperatures computed for the equivalent wind speed $\left(U_{10}^{\prime}\right)$ and the averaged wind speed $\left(\bar{U}_{10}\right)$. The error is negligible at nadir but increases with elevation angle reaching values around 0.22 and -0.2 for $T_{\mathrm{v}}$ and $T_{\mathrm{h}}$, respectively. This plot shows an opposite behavior with respect to the one in Fig. 2(c), which presents the brightness temperature error for an example of growing sea. Now, the error is positive for the horizontal polarization and negative for the vertical one. In the previous case, the estimated roughness was greater than the real one, while for decreasing sea the estimated roughness is lower than the real one. The tendency of the brightness temperature error is consistent with the emissivity dependence to the wind, and hence, to the sea surface roughness: an increment of the sea roughness produces an increment of $T_{\mathrm{h}}$ and a decrement of $T_{\mathrm{v}}$.

\section{Swell Effects}

The spectrum is usually the result of the local wind generated roughness and the swell propagated from other places. Plots in Fig. 4 corresponds to measurements on November 10, 2001 at 9 P.M. day of year $=314$ ) and show an example of the swell effect on the spectrum and its emissivity. The wind speed evolution during the previous $24 \mathrm{~h}$ is more constant than in the previous two examples, but in previous days [Fig. 5(a)] intense wind blew and significant wave heights (defined as the average of one third of the highest waves) of about $1.8 \mathrm{~m}$ were still present in the area [Fig. 5(b)].

Swell spectrum can be modeled by a narrowband Gaussian process with a 2-D roughness spectrum [17] with parameters: swell height variance $\left\langle h^{2}\right\rangle$, directional standard deviations $\sigma_{x}$ and $\sigma_{y}$, and swell spectral peak wave numbers $K_{x m}$ and $K_{y m}$, in the directions $x$ and $y$, respectively, which are not usually coincident with the up-wind and cross-wind directions

$$
\begin{aligned}
& \Psi_{\text {swell }}\left(K_{x}, K_{y}\right)=\frac{\left\langle h^{2}\right\rangle}{2 \pi \sigma_{x} \sigma_{y}} \\
& \quad \cdot \exp \left\{-\frac{1}{2}\left[\left(\frac{K_{x}-K_{x m}}{\sigma_{x}}\right)^{2}+\left(\frac{K_{y}-K_{y m}}{\sigma_{y}}\right)^{2}\right]\right\} .
\end{aligned}
$$

Then, the contribution of the swell to the omnidirectional spectrum can be obtained using the following relation:

$$
S_{\text {swell }}(K)=K \cdot \int_{-\pi}^{\pi} \Psi_{\text {swell }}(K, \phi) d \phi .
$$

Fig. 4(b) shows the omnidirectional sea surface spectrum measured by the wave rider buoy (solid line), the unified fully developed spectrum for 3-h averaged wind speed $\bar{U}_{10}=11.33 \mathrm{~m} / \mathrm{s}$ (dashed line), and this spectrum plus a swell spectrum $S_{\text {swell }}(K)$. The swell contribution to the spectrum has been obtained with the following parameters: $\langle h\rangle=0.28 \mathrm{~m}$, $\sigma_{x}=\sigma_{y}=0.011 \mathrm{~m}^{-1}$, and $K_{x m}=K_{y m}=0.043 \mathrm{rad} / \mathrm{m}$ (dotted line). These values have been chosen in order to minimize the difference between the measured spectrum and the wind-driven fully developed unified spectrum. It is clear that the combined model (dotted line) shows a better agreement with the measured spectrum than just the fully developed sea spectrum.

Fig. 4(c) shows the difference between the computed brightness temperatures at vertical and horizontal polarizations $\left(T_{\mathrm{v}}\right.$ and $T_{\mathrm{h}}$ ) when adding the swell effect or not. As in the previous case, the total roughness (swell and wind effects) is greater than the theoretical one. Therefore, the error for the vertical polarization is positive, whereas it is negative for the horizontal polarization. 
Finally, since the swell has a very directional behavior, in Fig. 6 the same difference (emissivity of a sea surface roughened by swell and wind and the one roughened only by wind) is plotted respect to azimuth angle as well. The azimuthal signature is quite small and decreases with the elevation angle. Fig. 6(a) and (b) shows the dependence of the error when the swell effect is neglected for the vertical and the horizontal polarizations, respectively. In those plots the swell and wind directions are the same. If the angle between the swell and the wind directions is $45^{\circ}$, this error is only shifted [see Fig. 6(c) and (d)]. In order to better appreciate this shifting, Fig. 6(e) and (f) plots the $\theta=30^{\circ}$ cut in those figures. A shift of $45^{\circ}$ is appreciated between dotted lines (swell and wind with the same direction) and solid line $\left(45^{\circ}\right.$ between the swell and the wind directions).

\section{CONCLUSION}

This paper demonstrates that it is important to know the actual sea state in the prediction of the L-band radiometric emission. First of all, fully developed wind-driven unified spectra computed with the 3 -h averaged measured wind at $10 \mathrm{~m} \bar{U}_{10}$ have been compared with the measured spectra during WISE campaigns, and a great disagreement has been appreciated. The measured spectra are defined with only 14 points and the accuracy of the emissivity method depends on the number of points used in the numerical integral. Hence, the energy of each measured spectrum has been calculated, and then, an equivalent wind speed at $10 \mathrm{~m}\left(U_{10}^{\prime}\right)$ has been estimated in order to obtain a fully developed wind-driven unified spectrum with the same energy as the measured one. Finally, the difference of the emissivity using the $U_{10}^{\prime}$ spectrum and the $\bar{U}_{10}$ spectrum, for the horizontal and the vertical polarizations has been computed and plotted with respect to the incidence angle. Three different situations have been analyzed: growing sea, decreasing sea and sea affected by swell. In all of them, the modulus of the difference tends to increase with the elevation angle. Differences of a fraction of a kelvin are found, which are not negligible when retrieving salinity from TB. These differences are in the same order of magnitude as the dependence of TB with respect to the sea surface salinity. In addition it has been observed that these differences have opposite sign for the vertical and the horizontal polarizations: when the roughness is overestimated $\Delta T_{\mathrm{h}}$ is positive and $\Delta T_{\mathrm{v}}$ is negative, whereas, when the roughness is underestimated the behavior is just the contrary. This is consistent with the emissivity dependence to the wind speed, and hence to the sea surface roughness: if the sea surface roughness increases the $T_{\mathrm{h}}$ increases and the $T_{\mathrm{v}}$ decreases. Therefore, because of this contrary behavior, this error can be minimized by using the first Stokes parameter $I=T_{\mathrm{v}} T_{\mathrm{h}}$ in the SSS retrieval algorithm [18].

The azimuthal dependence of the brightness temperature error when the swell effect in the spectrum is neglected has also been studied. This azimuthal dependence is always very small and decreases with the elevation angle. Azimuth angles with maximum error are shifted, if the angle between the wind and the swell directions changes.

\section{ACKNOWLEDGMENT}

The authors appreciate the cooperation provided by the personnel of Repsol Investigaciones Petrolíferas-Base TarragonaPlataforma Casablanca during WISE 2000 and 2001 campaigns. The wave-rider buoy measurements were provided by the Laboratoire d'Océanographie Dynamique et Climatologie (LODYC).

\section{REFERENCES}

[1] A. Camps, J. Font, J. Etchetto, V. Caselles, A. Weill, I. Corbella, M. Vall-llossera, N. Duffo, F. Torres, R. Villarino, L. Enrique, A. Julià, C. Gabarró, J. Boutin, E. Rubio, S. C. Reising, P. Wursteisen, M. Berger, and M. Martín-Neira, "Sea surface emissivity observations at L-band: First results of the wind and salinity experiment WISE-2000," IEEE Trans. Geosci. Remote Sensing, vol. 40, pp. 2117-2130, Oct. 2002.

[2] A. Camps, J. Font, J. Etcheto, A. Weill, V. Caselles, I. Corbella, M. Vall-llossera, F. Torres, N. Duffo, R. Villarino, L. Enrique, J. Miranda, A. Julià, C. Gabarró, J. Boutin, R. Niclós, P. Wursteisen, M. Berger, and M. Martín-Neira, "L-band sea surface emissivity radiometric observations under high winds: Preliminary results of the wind and salinity experiment WISE-2001," in Proc. IGARSS, 2002.

[3] J. A. Knauss, Introduction to Physical Oceanography. Upper Saddle River, NJ: Prentice-Hall, 1997.

[4] J. Miranda, M. Vall-llossera, A. Camps, and N. Duffo, "Sea surface emissivity at L-band: Swell effects experiment WISE-2001," in Proc. IGARSS, 2002.

[5] K. Hasselmann, "On the nonlinear energy transfer in a gravity-wave spectrum part general theory," J. Fluid Mech., vol. 15, no. 2, pp. 273-281, 1961.

[6] R. H. Stewart, Introduction to Physical Oceanography. College Station, TX: Texas A\&M Univ., 2001.

[7] B. Kinsman, Wind Waves. Their Generation and Propagation on the Ocean Surface. Mineola, NY: Dover, 1984

[8] T. Elfouhaily, B. Chapron, K. Katsaros, and D. Vandemark, "A unified directional spectrum for long and short wind-driven waves," J. Geophys. Res., vol. 102, no. C7, pp. 15 781-15 796, 1997.

[9] S. A. Kitaigorodskii, "Applications of the theory of similarity to the analysis of wind-generated wave motion as a stochastic process," IZV. Akad. Nauk SSSR, ser. Ser. Geofiz, vol. 1, p. 73, 1962.

[10] M. A. Donelan, J. Hamilton, and W. H. Hui, "Directional spectra of wind generated waves," Philos. Trans. R. Soc. London A, vol. 315, pp. 509-562, 1985.

[11] F. Dobson, W. Perrie, and B. Toulany, "On the deep-water fetch laws for wind-generated surface gravity waves," Atmos. Ocean, vol. 27, no. 1, pp. 210-236, 1989.

[12] I. R. Young, L. A. Verhagen, and M. L. Banner, "The evolution of wind generated waves in water of finite depth," in Proc. 2nd Int. Conf. Air-Sea Interaction and Meteorology and Oceanography of the Coastal Zone. Lisbon, Portugal, 1994.

[13] J. T. Johnson and M. Zhang, "Theoretical study of the small slope approximation for ocean polarimetric thermal emission," IEEE Trans. Geosci. Remote Sensing, vol. 37, pp. 2305-2316, Sept. 1999.

[14] N. Reul and B. Chapron, "SMOS—-salinity data processing study, improvements in emissivity models," ESA, Noordwijk, The Netherlands, Rep. WP 1100, 2001.

[15] F. T. Ulaby, R. K. Moore, and A. K. Fung, Microwave Remote Sensing Active and Passive. Norwood, MA: Artech House, 1990, vol. III, pp. $1560-1560$.

[16] A. G. Voronovich, "Small-slope approximation for electromagnetic wave scattering at rough interface of two dielectric half-spaces," Waves Random Media, vol. 4, pp. 337-367, 1994.

[17] S. L. Durden and J. F. Vesecky, "A physical radar cross-section model for a wind-driven sea with swell," IEEE J. Oceanic Eng., vol. OE-10, pp. 445-451, Oct. 1985.

[18] A. Camps, I. Corbella, M. Vall-llossera, N. Duffo, F. Torres, R. Villarino, L. Enrique, F. Julbé, J. Font, A. Julià, C. Gabarró, J. Etchetto, J. Boutin, A. Weill, V. Caselles, E. Rubio, P. Wursteisen, and M. Martín-Neira, "L-Band sea surface emissivity: Preliminary results of the WISE-2000 campaign and its application to salinity retrieval in the SMOS mission," Radio Sci., vol. 38, no. 4, 2003. 


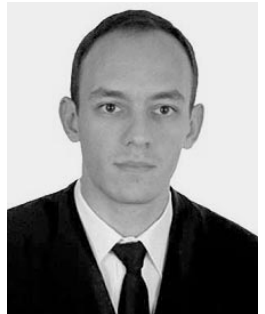

Jorge José Miranda was born in Las Palmas de Gran Canaria, Canary Islands, Spain, in 1973. He received the Telecommunication Technical Engineering degree from Las Palmas de Gran Canaria University (ULPGC), Spain, and the Senior Telecommunication Engineering degree from the Polytechnic University of Catalonia (UPC), Barcelona, Spain, in 1996 and 2001, respectively. He is currently pursuing the $\mathrm{Ph} . \mathrm{D}$. degree in telecommunication engineering from UPC

From 1996 to 1999 , he was with the Remote Sensing and Radar Laboratory (EUITT-ULPGC), where collaborated in satellite image processing. In 1999, he joined the Signal Theory and Communications Department, UPC. His Ph.D. thesis is focused on the sea surface emissivity at L-band. It includes the development of new models for determining the sea surface roughness and the comparison and improvement of existing emissivity models. Since 2002, he has been an Assistant Professor at the UPC.

Mercè Vall-llossera (M'99) received the Senior Telecommunication Engineer and the Doctor Telecommunication Engineering degrees in 1990 and 1994, respectively, both from the Polytechnic University of Catalonia (UPC), Barcelona, Spain.

She has been lecturing and doing research at the Department of Signal Theory and Communications, UPC from 1990 until 1997 as an Assistant Professor and from 1997 until present as an Associate Professor. She spent a sabbatical year in Montreal with the scholarship of the "Programme Québécois de Bourses d'excellence" (1996-1997): "Stages de Formation postdoctorale au Québec pour jeunes diplômés étrangers." Her research interests include numerical methods in electromagnetism, microwave radiometry, antenna analysis, and design. Currently, her research is mainly related to the study of numerical methods applied to the sea surface emissivity and their characterization at L-band and the MIRAS/SMOS project.

Dr. Vall-1lossera, along with the other member of the radiometry group at UPC, was awarded the "Primer Premio Duran Farell de Investigación Tecnológica" in 2002, and the "Primer Premio Ciutat de Barcelona d'Investigació Tecnològica" in 2001.

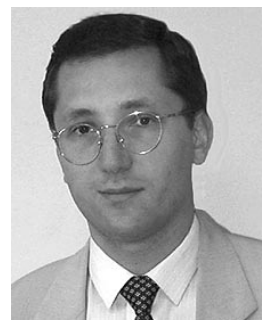

Adriano Camps (S'91-A'97-M'00-SM'02) was born in Barcelona, Spain, in 1969. He received the Telecommunications Engineering degree and the Ph.D. degree in telecommunications engineering in 1992 and 1996, respectively, both from the Polytechnic University of Catalonia (UPC), Barcelona, Spain.

From 1991 to 1992, he was with the ENS des Télécommunications de Bretagne, Bretagne, France, with an Erasmus Fellowship. In 1993, he joined the Electromagnetics and Photonics Engineering group, at the Department of Signal Theory and Communications, UPC, as an Assistant Professor, and since 1997 as an Associate Professor. In 1999, he was on sabbatical leave at the Microwave Remote Sensing Laboratory, University of Massachusetts, Amherst. His research interests are microwave remote sensing, with special emphasis in microwave radiometry by aperture synthesis techniques. He has performed numerous studies within the frame of European Space Agency SMOS Earth Explorer Mission. He is an Associate Editor of Radio Science.

Dr. Camps received the second national award of university studies in 1993, the INDRA award of the Spanish Association of Telecommunication Engineering to the best Ph.D. in 1997, the extraordinary Ph.D. award at the Universitat Politècnica de Catalunya in 1999, the First Duran Farell Award and the Ciudad de Barcelona Award, in 2000 and 2001, respectively, both for Technology Transfer; and in 2002, the Research Distinction of the Generalitat de Catalunya for contributions to microwave passive remote sensing. He was Chair of Cal ' $01 . \mathrm{He}$ is editor of the IEEE Geoscience and Remote Sensing Newsletter and President-Founder of the IEEE Geoscience and Remote Sensing Society Chapter at Spain.

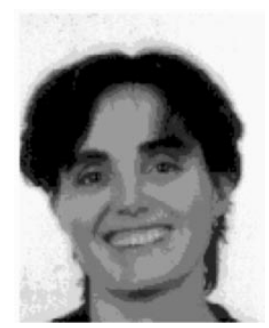

Núria Duffo (S'91-M'99) received the Telecommunication Engineer degree from the Polytechnic University of Catalonia (UPC), Barcelona, Spain, and the Doctor in Telecommunication Engineering from UPC, in 1990 and 1996, respectively.

Since 1997, she has been an Associate Professor at UPC. Her current research interests are numerical methods in electromagnetics, microwave radiometry, antenna analysis, and design.

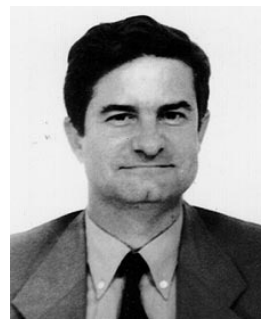

Ignasi Corbella (M'99) received the Telecommunications Engineering and Doctor Engineering degrees, both from Universitat Politècnica de Catalunya (UPC), Barcelona, Spain, in 1977 and 1983, respectively.

In 1976, he joined the School of Telecommunication Engineering in UPC as a Research Assistant in the Microwave Laboratory, were he worked on passive microwave integrated circuit design and characterization. During 1979, he worked at Thomson-CSF, Paris, France, on microwave oscillators design. In 1982, he became an Assistant Professor at UPC, an Associate Professor in 1986, and a Full Professor in 1993. He is currently teaching microwaves at the undergraduate level in UPC and has designed and taught graduate courses on nonlinear microwave circuits. During the school year 1998-1999, he worked at NOAA/Environmental Technology Laboratory, Boulder, CO, as a Guest Researcher, developing methods for radiometer calibration and data analysis. His research work in the Department of Signal Theory and Communications, UPC includes microwave airborne and satellite radiometry and microwave system design.

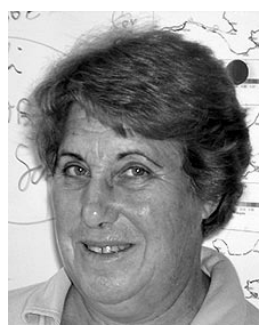

Jacqueline Etcheto was born in Meknes, Morocco, in 1943. She received the Agregation de Physique degree and the Docteur es Sciences Physiques degree for her thesis in space plasma physics in 1965 and 1972, respectively, both from the Ecole Normale Superieure de Jeunes Filles, Paris, France.

She became a Full-Time Scientist in Centre National de la Recherche Scientifique in 1965. She is presently appointed to Laboratoire d'Oceanographie Dynamique et de Climatologie, Paris, France, as Directeur de Recherches. From 1965 to 1987, she has been working on space plasma physics, focusing on studies of propagation and generation of waves in the magnetosphere. She was responsible for relaxation sounders onboard GEOS1 (ESA, 1977), GEOS2 (ESA, 1978), and ISEE1 (ESA/NASA, 1977), including instrument definition, provision of hardware, data handling, and scientific use of data. In 1988, she became interested in oceanography, using the synergy between remotely sensed measurements and in situ data to study the air-sea $\mathrm{CO} 2$ exchange at large scale. Her research activity is multiyear estimation of air-sea $\mathrm{CO} 2$ flux at regional scale using both satellite (wind speed, SST, ocean color) and in situ (PCO2 and related parameters, including launching CARIOCA buoys) data. Since 1999, she is involved in the preparation of the SMOS satellite (ESA, 2007) intended at determining sea surface salinity using L-band radiometry. She is interested in the development and validation of sea surface emissivity models at L-band, including validation campaigns. She is coordinating the group of French scientists involved in the ocean part of the SMOS project. She has published 77 papers in the open literature. 